\title{
Significance of splenic uptake on somatostatin receptor imaging studies
}

Ismet Sarikaya ${ }^{1}$, Ali Sarikaya ${ }^{2}$, Naheel Alnafisi ${ }^{3}$, Saud Alenezi ${ }^{1}$

${ }^{1}$ Kuwait University Faculty of Medicine, Department of Nuclear Medicine, Kuwait

${ }^{2}$ Trakya University Faculty of Medicine, Department of Nuclear Medicine, Edirne, Turkey

${ }^{3}$ Mubarak Al-Kabeer Hospital, Department of Nuclear Medicine, Kuwait

[Received 19 X 2017; Accepted 9 I 2018]

\begin{abstract}
Spleen shows a high physiological uptake on radionuclide somatostatin receptor (SSTR) imaging studies. Autoradiography and immunohistochemistry studies showed that SSTRs are mainly located in the red pulp of the spleen. In this review article we will summarize the significance of splenic uptake in SSTR imaging studies and will also present high resolution splenic images of Ga-68 DOTANOC PET in which splenic distribution of the radiotracer appears to be correlating with the distribution of red pulp.
\end{abstract}

KEY words: Spleen, somatostatin receptor, SSTR, radionuclide, red pulp, scintigraphy, Ga-68 DOTANOC

Nucl Med Rev 2018; 21, 1: 66-70

\section{Anatomic and physiologic considerations of spleen}

The spleen is a pulpy, oval shaped, dark red to blue-black colored, fist sized organ located in the left upper quadrant of the abdomen. Spleen is a highly vascular organ. It has 2 main compartments, the red pulp and the white pulp, which have distinct function and morphology. The red pulp is a blood filter that removes foreign materials and damaged and aged red blood cells (RBCs) from the circulation. It is also a storage site for iron, RBCs, and platelets. White pulp surrounds the central arterioles and is composed of periarteriolar lymphoid sheath, the follicles, and the marginal zone. Spleen lacks afferent lymphatic vessels. Through efferent vessels lymphocytes migrate to the splenic lymph nodes. Immune responses to blood-borne antigens occurs in the white pulp [1]. The spleen is the largest secondary lymphoid organ which carries about one-fourth of the body's lymphocytes [1].

\section{Somatostatin and somatostatin receptors}

Somatostatin (SST) is a regulatory peptide which is secreted by various tissues, mainly digestive system (delta cells in pancreatic islets, duodenum and pyloric antrum) and also nervous system (neuroendocrine cells). SST exhibits various neuroendocrine, gastrointestinal and neuromodulatory effects. SST has two biologically active forms; SST14 and SST28.

Correspondence to: Ismet Sarikaya, MD, ABNM, Assoc. Professor, Department of Nuclear Medicine, Faculty of Medicine, Kuwait University, PO Box 24923, Safat, Kuwait 13110, phone: (965) 25319592 / 6414, fax: (965) 25338936, e-mail: isarikaya99@yahoo.com
Major action of SST is inhibition of hormone secretion from the pituitary gland, the pancreas and other endocrine tissues and exocrine secretions in various sites [2]. SST inhibits release of growth hormone, prolactin, thyroid-stimulating hormone (TSH), and adrenocorticotropic hormone (ACTH) from the anterior pituitary gland, insulin and glucagon from the pancreas and gastrin, vasoactive intestinal peptide, secretin and cholecystokinin from the gastrointestinal tract. Inhibitory effects of SST on various gastrointestinal functions include gastric acid secretion, gastric emptying, and intestinal motility. Its neuromodulatory effects are involved in learning, cognitive functions, locomotor activity, anxiety, and depression [3]. SST also exerts antiproliferative actions on normal and cancer cells via inducing cell cycle arrest and apoptosis and also takes part in immunoregulation [4-6].

SST exerts its effects through binding to SST receptor (SSTR) subtypes. There are 5 SSTR subtypes: SSTR1, SSTR2A and B, SSTR3, SSTR4 and SSTR5. SSTRs belong to the G protein coupled receptor family and widely expressed in normal tissues and solid tumors [7].

SSTR subtypes are expressed throughout the human body, including the central nervous system, gastrointestinal tract, pancreas, kidney, prostate, thyroid, and most lymphatic tissues including gut-associated lymphatic tissue, spleen and thymus.

Autoradiography and immunohistochemistry studies demonstrated that SSTRs were mainly located in the red pulp of the spleen which contains diffusely distributed SSTRs [8-10]. The most abundant SSTR subtype in the spleen was SSTR2 (79.7\%) followed by SSTR1 (19.6\%), SSTR4 (0.6\%), SSTR3 (0.1\%) and SSTR5 (0.0\%) [11]. Significantly higher expression of SST2A mRNA in the spleen was demonstrated by quantitative reverse transcription polymerase chain reaction [12]. Fluorescence immunocytochemistry revealed the presence of SST-positive cells in clusters inside the white pulp 
and more dispersed within the red pulp of the spleen of both the rat and the chicken [13].

SSTRs have also been identified in a large number of human tumors, mainly in a high density in neuroendocrine tumors (NETs) such as pituitary adenoma, pancreatic islet cell tumor, carcinoid, pheochromocytoma, paraganglioma, medullary thyroid cancer, and small cell lung carcinoma and tumors of the nervous system including meningioma, neuroblastoma, and medulloblastoma [14, 15]. The other tumors such as lymphoma, breast cancer, renal cell cancer, hepatocellular cancer, prostate cancer, sarcoma, and gastric cancer, may also express SSTRs [15].

\section{Radionuclide SSTR imaging}

Radionuclide SSTR imaging is used for the detection, localization, staging and in follow-up of NETs. It is useful in the selection of patients for SSTR based therapy with cold or radiolabeled SST analogs [16, 17]. It helps monitoring response to treatment [18]. It may be used in other non-NET tumors expressing SSTRs such as lymphoma and in active inflammatory disorders such as sarcoidosis $[19,20]$.

SSTR imaging with radiolabeled SST analogs have been used since late 1980s. In early studies I-123 Tyr-3-Octreotide was used which was later replaced by In-111 pentetreotide (Octreotide scintigraphy, OctreoScan). Currently, there are new Ga-68 labeled SST analogs for positron emission tomography (PET) imaging [21]. I-125 TYR(3)-octreotide was studied for hand held gamma probe tumor detection [22]. Tc-99m labeled SST analogs are also available but not commonly used [23].

The main SSTR subtype(s) targeted by various radiotracers are as follows: SSTR2 and SSTR5 by In-111 pentetreotide, SSTR2 by Ga-68 DOTATATE, SSTR2 and SSTR5 by Ga-68 DOTATOC, and SSTR2, SSTR3 and SSTR5 by Ga-68 DOTANOC.

Conventional SSTR imaging with In-111 pentetreotide is still widely used in the detection of NETs. However, new Ga-68 labeled PET radiotracers have been increasingly used and replacing conventional SSTR imaging in many centers due better properties of both the PET radiotracers and PET cameras over In-111 pentetreotide and gamma cameras with single photon emission computed tomography (SPECT) imaging. Studies have shown the superiority of PET imaging with Ga-68 DOTA peptides over SPECT imaging with In-111 pentetreotide for NETs [24, 25].

As compared to In-111 pentetreotide imaging, PET scan with Ga-68 DOTA peptides detects more lesions, shows higher uptake in the lesions and provides shorter time of acquisition and lower radiation exposure $[24,26]$.

\section{Splenic uptake on SSTR imaging studies}

Spleen shows the highest physiological uptake on radionuclide SSTR imaging studies using any of the available radiolabeled SST analogs and it receives the highest radiation dose (critical organ). The reported radiation dosimetry results for the spleen using $\mathrm{In}-111$ pentetreotide are $0.57 \mathrm{mGy} / \mathrm{MBq}(2.1 \mathrm{rad} / \mathrm{mCi})$ in adults, $0.79 \mathrm{mGy} / \mathrm{MBq}(2.9 \mathrm{rad} / \mathrm{mCi})$ in 15 year old children, and $1.8 \mathrm{mGy} / \mathrm{MBq}(6.7 \mathrm{rad} / \mathrm{mCi})$ in 5 year old children [27]. Splenic radiation dose in Ga-68 DOTANOC PET studies (without including $\mathrm{CT})$ is $0.0725 \mathrm{mGy} / \mathrm{MBq}(0.269 \mathrm{rad} / \mathrm{mCi})$ [28].
Studies have shown that SSTRs are mainly located in the red pulp of the spleen. However, it is not very clear that where exactly in red pulp SSTRs are located. Following SST administration there was a marked constriction of the splenic vascular bed with $50 \%$ decrease in blood flow which was suggested that this effect of SST was due to a direct action on vascular receptor sites [29]. Given high amount of SSTRs in the spleen, it is expected SSTRs to be located also on other sites in red pulp in addition to vascular structures.

To better assess splenic involvement by SSTR positive tumors, intensity of the image setting should be reduced. Due to intense uptake in the spleen, tumors with low or moderate SSTR expression may be missed or seen as cold defects. Uptake in the accessory spleen or splenosis may cause false positive result for SSTR positive tumors [30]. Studies have reported that radiotracer uptake in splenosis is less than the normal splenic uptake [31,32].

Spleen receives the highest mean absorbed dose during peptide receptor radionuclide therapy. Hematological toxicity according to hemoglobin counts was moderately but significantly correlated with total absorbed spleen dose which supported the possibility that radiation exposure of the spleen affects overall hematological response during Lu-177 DOTATATE treatment [33]. On the other hand, a previous study has reported that hematological toxicity after peptide receptor radionuclide therapy is not related to the radiation dose to the spleen [34]. In patients with NET undergoing peptide receptor radionuclide therapy, the uptake of Ga-68 DOTATOC in spleen and other normal tissues was not significantly different in pre and post-treatment [35].

Radionuclide SSTR imaging studies should be interpreted cautiously for treatment response evaluation in patients who underwent splenectomy after initial treatment. It was reported that there was higher uptake of Ga-68 DOTATOC in tumors and some normal tissues such as kidneys and adrenals after splenectomy [36].

In certain situations splenic uptake can be lower than the expected normal uptake. Treatment with cold SST analogs usually reduces splenic uptake of radiotracers for SSTR imaging [27, 37-39]. Several studies showed that treatment with cold SST analogs reduced the uptake in the spleen as well as in liver and kidneys, but it did not affect or even increased the uptake in the tumor [37-39]. Dörr et al. reported that liver, spleen, and kidney uptake were decreased during octreotide treatment but increased on lanreotide therapy, and tumor accumulation was intensified in majority of the patients [40].

Low physiological splenic uptake of Ga-68 DOTANOC has been reported in a newborn [41]. Authors of this case suggested that incomplete/immature expression of the SSTR in early life could be the reason for low splenic uptake. In-111 pentetreotide images of one of our patients who is a 7 year old child demonstrate less intense uptake in the spleen as compared normal which could be due to treatment with SST analogs (Fig. 1).

Spleen can be used as a reference to calculate tumor to spleen uptake ratio for estimation of SSTR density in tumors. Kratochwil et al. assessed the SSTR2 expression of the liver metastases in NET patients at baseline and after peptide receptor radiation therapy by measuring SUVmax, tumor to spleen ratio (T/S ratio), and tumor to liver ratio (T/L ratio) using Ga-68 DOTATOC [42]. Using the receiver operating characteristic curves, SUVmax was found a better metric than both $\mathrm{T} / \mathrm{L}$ ratio and $\mathrm{T} / \mathrm{S}$ ratios as a stratification criterion in this study. In another study with Ga-68 DOTATATE, SUVmax and 


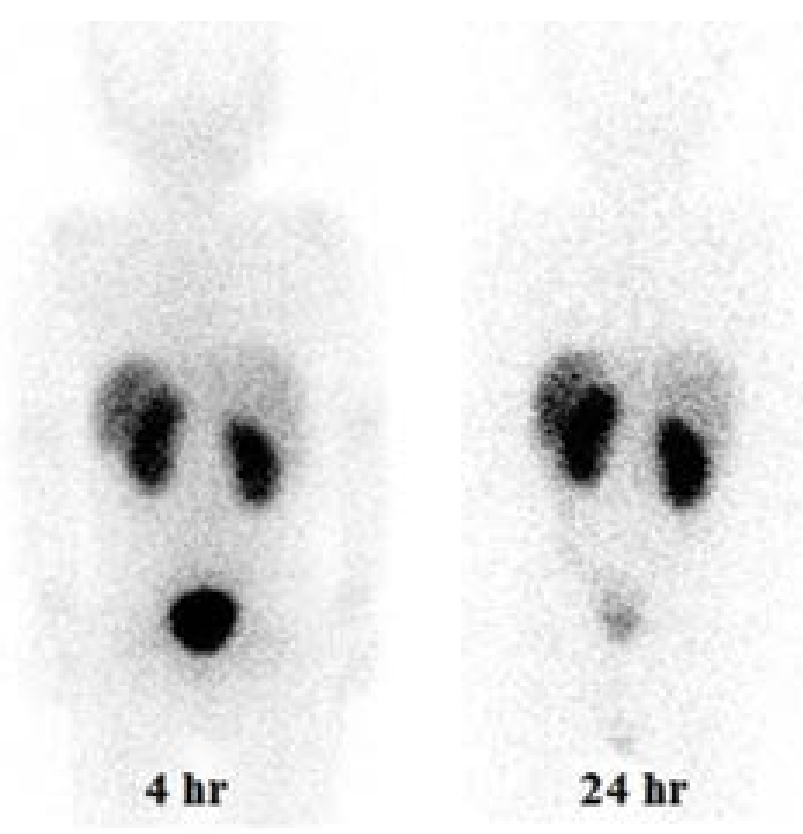

Figure 1. Four and $24 \mathrm{hr} \ln -111$ pentetreotide posterior whole body images of a 7 year old child illustrate less intense splenic uptake than the normal

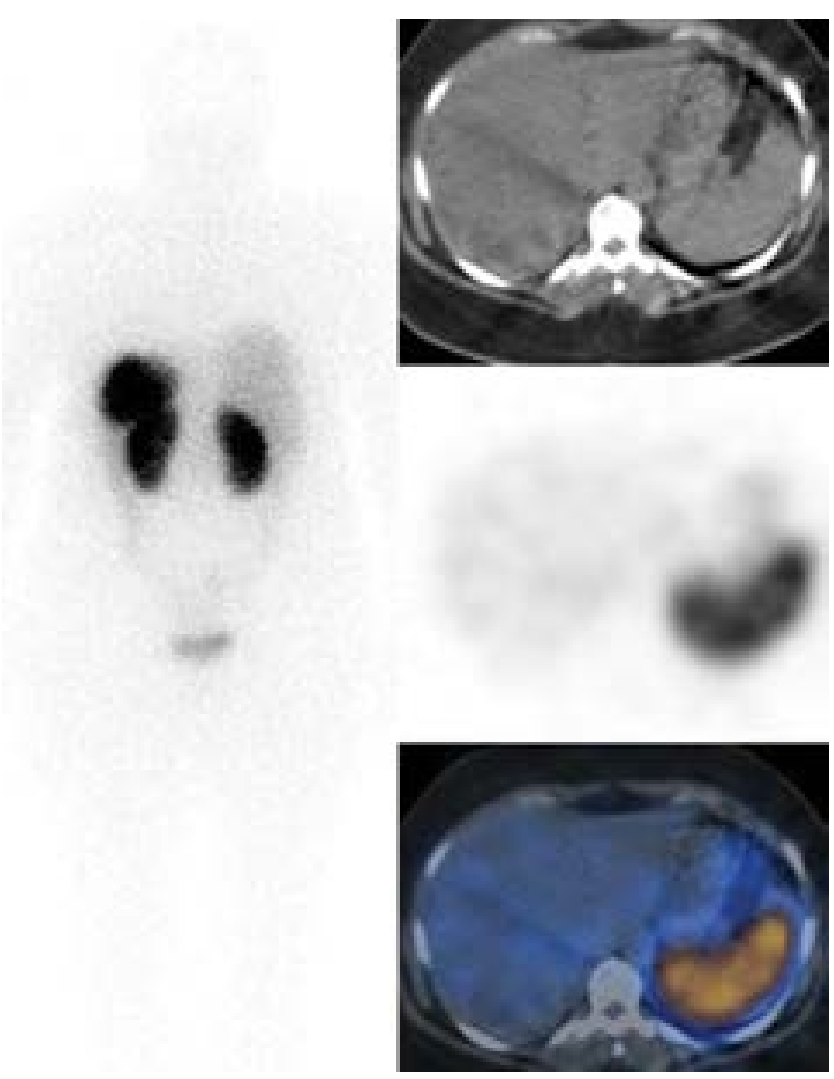

Figure 2. In-111 pentetreotide posterior whole body image and selected transaxial CT, SPECT, and SPECT/CT fusion images of the spleen. Note the high physiological uptake in the spleen with slight heterogeneous distribution

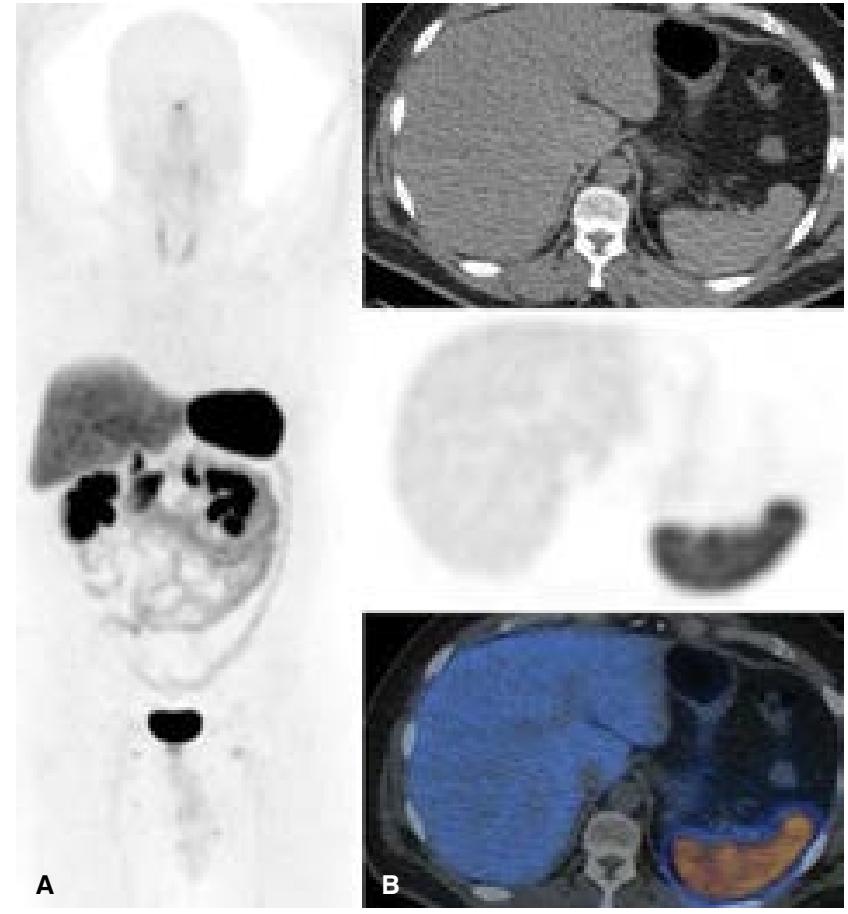

Figure 3. Ga-68 DOTANOC whole body MIP (A), and selected transaxial $\mathrm{CT}$, PET, and PET/CT fusion (B) images. PET images demonstrate physiological high uptake in the spleen. Compare the better image resolution of Ga-68 DOTANOC with In-111 Octreotide images in Figure 2. Note the slightly more prominent uptake in the periphery of the spleen which is likely from subcapsular red pulp. Areas showing less degree of uptake more centrally in the splenic parenchyma could be from splenic vascular structures and/or white pulp

tumor-to-spleen SUV ratio (SUV T/S) were used to assess for the early prediction of response to SST receptor-mediated radionuclide therapy in patients with well-differentiated NETS [43]. Percentage change in SUV scores after PRRT relative to baseline (DeltaSUV) was calculated. Delta SUV(T/S) was superior to Delta SUV (max) for prediction of outcome.

On SSTR images spleen shows diffuse high uptake with mild heterogeneity. In various studies with Ga-68 DOTATOC, standardized uptake value (SUVmax) (mean \pm standard deviation) in normal spleen was reported to be as $22.0 \pm 10.0,28.8 \pm 12.5$ and $31.1 \pm 10.9[11,31,44]$. SSTR PET images provide higher resolution spleen images than SSTR SPECT does (Fig. 2-4). Reducing intensity of the image settings helps better assess distribution of activity in the splenic parenchyma. On Ga-68 DOTANOC PET images, slightly heterogeneous distribution of activity with small areas showing less uptake than the rest of the parenchyma are likely due to vascular structures or regions of white pulp. Slightly more prominent uptake in the periphery of the spleen (subcapsular) and throughout parenchyma is likely from red pulp.

Because of high splenic uptake, SSTR imaging, particularly with PET radiotracers, may be an alternative to standard radionuclide splenic imaging studies with Tc-99m heat damaged RBCs or Tc-99m 

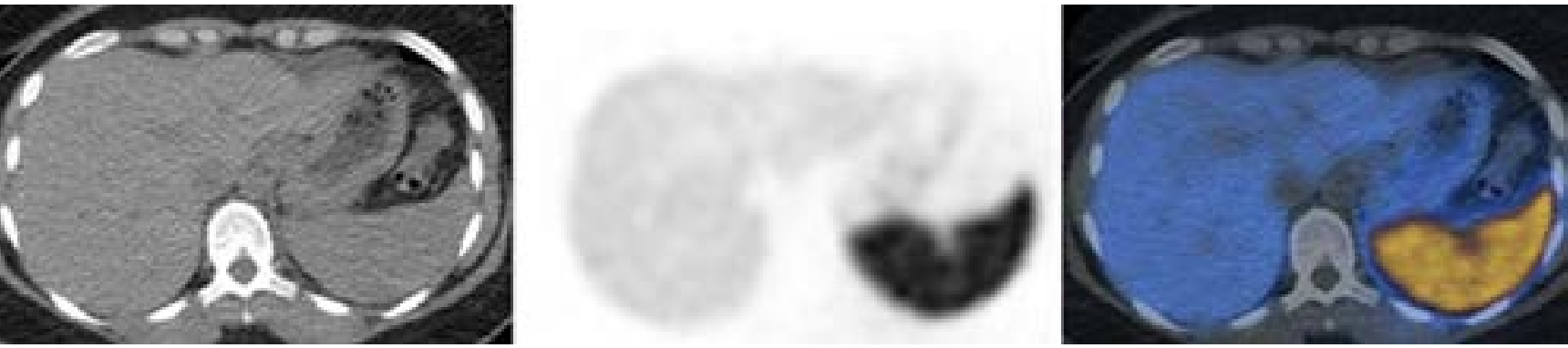

Figure 4. Ga-68 DOTANOC and selected transaxial CT, PET, and PET/CT fusion images demonstrate the distribution of radiotracer in the spleen which is correlating with distribution of red pulp as also shown in Figure 3

sulfur colloid (Tc-99m SC). Standard radionuclide splenic imaging studies are the procedure of choice to image spleen, however, they have certain limitations. Tc-99m heat damaged RBC study is laborious, time consuming, and requires strict sterile technique [45]. Insufficient or excessive damage to RBCs can also cause suboptimal study. Colloid scan with Tc-99m SC is less sensitive than selective spleen imaging in the identification of small splenic tissues because intense hepatic uptake can obscure small splenic tissues [46]. PET images of spleen with Ga-68 DOTA peptides have better resolution than standard radionuclide SPECT images of the spleen. PET study is also quicker and easier to perform. Radiation dose to spleen also appears to be lower with Ga-68 DOTANOC PET imaging (without including CT) than with Tc-99m heat damaged RBC scintigraphy $[27,28]$. However, the main limitations of PET imaging of spleen with Ga-68 DOTA peptides are the high cost and limited availability of this radiotracer.

\section{Conclusion}

Spleen shows a very high uptake in radionuclide SSTR imaging studies. Significance of splenic uptake on SSTR imaging studies have been summarized in this article. In addition it was noted that Ga-68 DOTA peptides provide high resolution images of the spleen which appears to be correlating with the distribution of red pulp. Because of high splenic uptake and excellent image quality, particularly with PET tracers, SSTR imaging may be an alternative to standard radionuclide splenic imaging studies to assess the spleen and detect accessory spleen and splenosis.

\section{References}

1. Cesta MF. Normal structure, function, and histology of the spleen. Toxicol Pathol. 2006; 34(5): 455-465, doi: 10.1080/01926230600867743, indexed in Pubmed: 17067939.

2. Olias $\mathrm{G}$, Viollet $\mathrm{C}$, Kusserow $\mathrm{H}$, et al. Regulation and function of somatostatin receptors. J Neurochem. 2004; 89(5): 1057-1091, doi: 10.1111/j.1471-4159.2004.02402.x, indexed in Pubmed: 15147500.

3. Ando H. Chapter 5: Somatostatin. In: Takei Y, Tsutsui K, Ando H. ed. Handbook of Hormones: Handbook of Hormones: Comparative Endocrinology for Basic and Clinical Research Comparative Endocrinology for Basic and Clinical Research. 2016: 36-38.

4. He Y, Yuan XM, Lei P, et al. The antiproliferative effects of somatostatin receptor subtype 2 in breast cancer cells. Acta Pharmacol Sin. 2009; 30(7): 1053-1059, doi: 10.1038/aps.2009.59, indexed in Pubmed: 19575008.
5. Weinstock JV, Elliott D. The somatostatin immunoregulatory circuit present at sites of chronic inflammation. Eur J Endocrinol. 2000; 143 Suppl 1: S15-S19, doi: 10.1530/eje.0.143s015, indexed in Pubmed: 11068935.

6. Stanisz AM, Scicchitano R, Payan DG, et al. In vitro studies of immunoregulation by substance P and somatostatin. Ann N Y Acad Sci. 1987; 496: 217-225, doi: 10.1111/j.1749-6632.1987.tb35769.x, indexed in Pubmed: 2440366.

7. Theodoropoulou M, Stalla GK. Somatostatin receptors: from signaling to clinical practice. Front Neuroendocrinol. 2013; 34(3): 228-252, doi: 10.1016/j.yfrne.2013.07.005, indexed in Pubmed: 23872332.

8. Reubi JC, Waser B, Horisberger $\mathrm{U}$, et al. In vitro autoradiographic and in vivo scintigraphic localization of somatostatin receptors in human lymphatic tissue. Blood. 1993; 82(7): 2143-2151, indexed in Pubmed: 8400264.

9. Melis M, Kaemmerer D, de Swart J, et al. Localization of Radiolabeled Somatostatin Analogs in the Spleen. Clin Nucl Med. 2016; 41(2): e111-e114, doi: 10.1097/RLU.0000000000001026, indexed in Pubmed: 26462044

10. Reubi JC, Horisberger U, Kappeler A, et al. Localization of receptors for vasoactive intestinal peptide, somatostatin, and substance $P$ in distinct compartments of human lymphoid organs. Blood. 1998; 92(1): 191-197, indexed in Pubmed: 9639516.

11. Boy C, Heusner TA, Poeppel TD, et al. 68Ga-DOTATOC PET/CT and somatostatin receptor (sst1-sst5) expression in normal human tissue: correlation of sst2 mRNA and SUVmax. Eur J Nucl Med Mol Imaging. 2011; 38(7): 1224-1236, doi: 10.1007/s00259-011-1760-X, indexed in Pubmed: 21369945.

12. Ferone D, Pivonello R, Kwekkeboom DJ, et al. Immunohistochemical localization and quantitative expression of somatostatin receptors in normal human spleen and thymus: Implications for the in vivo visualization during somatostatin receptor scintigraphy. J Endocrinol Invest. 2012; 35(5): 528-534, doi: 10.3275/7871, indexed in Pubmed: 21765239.

13. Aguila MC, Dees WL, Haensly WE, et al. Evidence that somatostatin is localized and synthesized in lymphoid organs. Proc Natl Acad Sci U S A. 1991; 88(24): 11485-11489, doi: 10.1073/pnas.88.24.11485, indexed in Pubmed: 1684864

14. Reubi JC, Schaer JC, Markwalder R, et al. Distribution of somatostatin receptors in normal and neoplastic human tissues: recent advances and potential relevance. Yale J Biol Med. 1997; 70(5-6): 471-479, indexed in Pubmed: 9825475.

15. Kwekkeboom D, Krenning E. Somatostatin receptor imaging. Seminars in Nuclear Medicine. 2002; 32(2): 84-91, doi: 10.1053/snuc.2002.31022.

16. van Essen M, Krenning EP, Kam BLR, et al. Peptide-receptor radionuclide therapy for endocrine tumors. Nat Rev Endocrinol. 2009; 5(7): 382-393, doi: 10.1038/nrendo.2009.105, indexed in Pubmed: 19488074.

17. Miederer M, Seidl S, Buck A, et al. Correlation of immunohistopathological expression of somatostatin receptor 2 with standardised uptake values in 68Ga-DOTATOC PET/CT. Eur J Nucl Med Mol Imaging. 2009; 36(1): 48-52, doi: 10.1007/s00259-008-0944-5, indexed in Pubmed: 18807033. 
18. Gabriel M, Oberauer A, Dobrozemsky G, et al. 68Ga-DOTA-Tyr3-octreotide PET for assessing response to somatostatin-receptor-mediated radionuclide therapy. J Nucl Med. 2009; 50(9): 1427-1434, doi: 10.2967/jnumed.108.053421, indexed in Pubmed: 19690033.

19. Reisinger I, Bohuslavitzki KH, Brenner W, et al. Somatostatin receptor scintigraphy in small-cell lung cancer: results of a multicenter study. J Nucl Med. 1998; 39(2): 224-227, indexed in Pubmed: 9476922.

20. Kwekkeboom D, Krenning E, Kho G, et al. Somatostatin receptor imaging in patients with sarcoidosis. European Journal of Nuclear Medicine and Molecular Imaging. 1998; 25(9): 1284-1292, doi: 10.1007/s002590050297.

21. Becker W, Marienhagen J, Scheubel R, et al. Octreotide scintigraphy localizes somatostatin receptor-positive islet cell carcinomas. Eur J Nucl Med. 1991; 18(11): 924-927, doi: 10.1007/bf02258458, indexed in Pubmed: 1684323.

22. Benevento A, Dominioni L, Carcano G, et al. Intraoperative localization of gut endocrine tumors with radiolabeled somatostatin analogs and a gamma-detecting probe. Semin Surg Oncol. 1998; 15(4): 239-244, doi: 10.1002/(sici)1098-2388(199812)15:4<239::aid-ssu11>3.0.co;2-4, indexed in Pubmed: 9829380

23. Płachcińska A, Mikołajczak R, Kozak J, et al. Comparative analysis of 99mTc-depreotide and 99mTc-EDDA/HYNIC-TOC thorax scintigrams acquired for the purpose of differential diagnosis of solitary pulmonary nodules. Nucl Med Rev Cent East Eur. 2006; 9(1): 24-29, indexed in Pubmed: 16791800

24. Kowalski J, Henze M, Schuhmacher J, et al. Evaluation of positron emission tomography imaging using [68Ga]-DOTA-D Phe(1)-Tyr(3)-Octreotide in comparison to [111ln]-DTPAOC SPECT. First results in patients with neuroendocrine tumors. Mol Imaging Biol. 2003; 5(1): 42-48, doi: 10.1016/s15361632(03)00038-6, indexed in Pubmed: 14499161.

25. Gabriel M, Decristoforo C, Kendler D, et al. 68Ga-DOTA-Tyr3-octreotide PET in neuroendocrine tumors: comparison with somatostatin receptor scintigraphy and CT. J Nucl Med. 2007; 48(4): 508-518, doi: 10.2967/jnumed.106.035667, indexed in Pubmed: 17401086.

26. Buchmann I, Henze M, Engelbrecht S, et al. Comparison of 68Ga-DOTATOC PET and 111ln-DTPAOC (Octreoscan) SPECT in patients with neuroendocrine tumours. Eur J Nucl Med Mol Imaging. 2007; 34(10): 1617-1626, doi: 10.1007/s00259-007-0450-1, indexed in Pubmed: 17520251.

27. Balon HR, Brown TLY, Goldsmith SJ, et al. Society of Nuclear Medicine. The SNM practice guideline for somatostatin receptor scintigraphy 2.0. J Nucl Med Technol. 2011; 39(4): 317-324, doi: 10.2967/jnmt.111.098277, indexed in Pubmed: 22068564

28. Pettinato C, Sarnelli A, Di Donna M, et al. 68Ga-DOTANOC: biodistribution and dosimetry in patients affected by neuroendocrine tumors. Eur J Nucl Med Mol Imaging. 2008; 35(1): 72-79, doi: 10.1007/s00259-007-0587-y, indexed in Pubmed: 17874094

29. Samnegård $H$, Tydén $G$, Thulin $L$, et al. Effect of somatostatin on regional splanchnic blood flows in man. Angiographic studies. Acta Chir Scand Suppl. 1980; 500: 71-73, indexed in Pubmed: 6111881

30. Lebtahi R, Cadiot G, Marmuse JP, et al. False-positive somatostatin receptor scintigraphy due to an accessory spleen. J Nucl Med. 1997; 38(12): 1979-1981, indexed in Pubmed: 9430481.

31. Kulkarni HR, Prasad V, Kaemmerer D, et al. High uptake of (68)Ga-DOTATOC in spleen as compared to splenosis: measurement by PET/CT. Recent Results Cancer Res. 2013; 194: 373-378, doi: 10.1007/978-3-642-279942 19, indexed in Pubmed: 22918769.
32. Reindl O, Loidl A, Franz B, et al. Pitfall in follow-up imaging of pancreatic neuroendocrine tumor by somatostatin receptor PET. Neuro Endocrinol Lett. 2013; 34(4): 273-274, indexed in Pubmed: 23803870.

33. Svensson J, Hagmarker L, Magnander T, et al. Radiation exposure of the spleen during (177)Lu-DOTATATE treatment and its correlation with haematological toxicity and spleen volume. EJNMMI Phys. 2016; 3(1): 15, doi: 10.1186/s40658-016-0153-4, indexed in Pubmed: 27491429.

34. Kulkarni HR, Prasad V, Schuchardt C, et al. Is there a correlation between peptide receptor radionuclide therapy-associated hematological toxicity and spleen dose? Recent Results Cancer Res. 2013; 194: 561-566, doi: 10.1007/978-3-642-27994-2 33, indexed in Pubmed: 22918783.

35. Giesel FL, Stefanova M, Schwartz LH, et al. Impact of peptide receptor radionuclide therapy on the 68Ga-DOTATOC-PET/CT uptake in normal tissue. Q J Nucl Med Mol Imaging. 2013; 57(2): 171-176, indexed in Pubmed: 23370092

36. Kratochwil C, Mavriopoulou E, Rath D, et al. Comparison of 68Ga-DOTATOC biodistribution in patients with and without spleenectomy. Q J Nucl Med Mol Imaging. 2015; 59(1): 116-120, indexed in Pubmed: 24382404

37. Haug AR, Rominger A, Mustafa M, et al. Treatment with octreotide does not reduce tumor uptake of (68)Ga-DOTATATE as measured by PET/CT in patients with neuroendocrine tumors. J Nucl Med. 2011; 52(11): 1679-1683, doi: 10.2967/jnumed.111.089276, indexed in Pubmed: 21976529.

38. Soresi E, Bombardieri E, Chiti A, et al. Indium-111-DTPA-octreotide scintigraphy modulation by treatment with unlabeled somatostatin analogue in small-cell lung cancer. Tumori. 1995; 81: 125-127.

39. Janson ET, Kälkner KM, Eriksson B, et al. Somatostatin receptor scintigraphy during treatment with lanreotide in patients with neuroendocrine tumors. Nucl Med Biol. 1999; 26(8): 877-882, doi: 10.1016/s0969-8051(99)00059-1, indexed in Pubmed: 10708300.

40. Dörr U, Wurm K, Höring E, et al. Diagnostic reliability of somatostatin receptor scintigraphy during continuous treatment with different somatostatin analogs. Horm Metab Res Suppl. 1993; 27: 36-43, indexed in Pubmed: 8330870.

41. Kumar G, Dhull VS, Karunanithi S, et al. Ga-DOTANOC PET/CT mimicking renal dynamic scan: lack of physiological uptake in the spleen of a newborn and the pituitary gland in congenital hyperinsulinism. Rev Esp Med Nucl Imagen Mol. 2014; 33(6): 382-383, doi: 10.1016/j.remn.2013.12.002, indexed in Pubmed: 25043776.

42. Kratochwil C, Stefanova M, Mavriopoulou E, et al. SUV of [68Ga]DOTATOC-PET/CT Predicts Response Probability of PRRT in Neuroendocrine Tumors. Mol Imaging Biol. 2015; 17(3): 313-318, doi: 10.1007/s11307-0140795-3, indexed in Pubmed: 25319765.

43. Haug AR, Auernhammer CJ, Wängler B, et al. 68Ga-DOTATATE PET/CT for the early prediction of response to somatostatin receptor-mediated radionuclide therapy in patients with well-differentiated neuroendocrine tumors. J Nucl Med. 2010; 51(9): 1349-1356, doi: 10.2967/jnumed.110.075002, indexed in Pubmed: 20720050

44. Prasad V, Baum RP. Biodistribution of the Ga-68 labeled somatostatin analogue DOTA-NOC in patients with neuroendocrine tumors: characterization of uptake in normal organs and tumor lesions. Q J Nucl Med Mol Imaging. 2010; 54(1): 61-67, indexed in Pubmed: 20168287.

45. MacDonald A, Burrell S. Infrequently performed studies in nuclear medicine: Part 1. J Nucl Med Technol. 2008; 36(3): 132-43; quiz 145, doi: 10.2967/jnmt.108.051383, indexed in Pubmed: 18703616.

46. Massey MD, Stevens JS. Residual spleen found on denatured red blood cell scan following negative colloid scans. J Nucl Med. 1991; 32: 2286-2287. 